\title{
A Review of Structural Performance of Oil Palm Empty Fruit Bunch Fiber in Polymer Composites
}

\author{
Reza Mahjoub, Jamaludin Bin Mohamad Yatim, and Abdul Rahman Mohd Sam \\ Civil Engineering Faculty, Universiti Teknologi Malaysia, P.O. Box 81310, Skudai, Johor Bahru, Malaysia \\ Correspondence should be addressed to Reza Mahjoub; r_mahjoob@yahoo.com
}

Received 4 September 2012; Revised 13 December 2012; Accepted 19 December 2012

Academic Editor: Markku Leskela

Copyright ( 2013 Reza Mahjoub et al. This is an open access article distributed under the Creative Commons Attribution License, which permits unrestricted use, distribution, and reproduction in any medium, provided the original work is properly cited.

\begin{abstract}
According to environmental concerns and financial problems, natural fibers have become interesting and fascinating nowadays to be used as an industrial material and structural material for rehabilitating of structures. Oil palm empty fruit bunch fiber (OPF) is a natural fiber which is found a lot in tropical areas. Scientists have used OPF fiber with many types of resins such as epoxy, polypropylene, polyester, and phenol formaldehyde. Therefore, this paper focused on the properties of OPF fiber and gathered mechanical properties of OPF composites (OPF as reinforcement of polymer) reported by other researchers in terms of tensile and flexural properties. Furthermore, the chemical surface modification methods to solve the interfacial bonding of fiber and polymer were mentioned. In addition, the results of hybrid composites of OPF were also discussed in this paper. Meanwhile, the results of composites were compared to pure resin properties and also the stress-strain diagram and internal strain energy of composites were considered. Besides, the effects of adding OPF to other composites to make a new hybrid composite were indicated. Finally, it is clear that the use of oil palm fiber composites for structural elements for bearing loads is not recommended but the usage of OPF composites for secondary structural elements may be recommended due to future researches.
\end{abstract}

\section{Introduction}

The possibility of using of fiber reinforced polymer (FRP) researches for rehabilitating started at the beginning of the nineties [1]. Several methods for using of some kind of fibers have been reported by engineers, and also composites characterizations have been investigated by researchers in recent years. There are two major types of fiber used usually in engineering consist of synthetic or man-made fibers and natural or biofibers. Synthetic fibers have some advantages such as high strength, high modulus, light weight and easy installation [2-5]. On the other hand, bio fibers have a renewable and biodegradable nature and low energy consumption during processing and also they are ecofriendly and cheaper than man-made fibers [6-9]. Therefore, engineers and researchers have been attracted to use natural fibers for industrial applications. One of these natural fibers is Oil Palm Empty Fruit bunch (OPF) fiber found a lot in tropical region. The major source of OPF is the empty fruit bunch of oil palm trees after extracting oil in the factory. Nowadays, the oil palm empty fruit bunch is used as fuel, fertilizer, and a mulching material and in making fiber because the remaining of this waste material can make environmental issues [10]. One of the important issues of natural fiber is the hydrophilic property of cellulose which impacts the weak interface bonding with hydrophobic polymer as a matrix. Consequently, chemical surface modification methods of natural fiber are well documented in literature including alkaline treatment, acidity treatment, and coupling agents to improve this issue. Many experimental studies have been conducted and results reported for investigating the mechanical and physical properties of OPF composites recently. So by gathering information from the other researches and analyzing them, it can be possible to know how OPF fiber affects polymer composites and predict how OPF fiber can be used for the rehabilitators of structural elements of concrete construction. This paper has considered the tensile strength, tensile modulus, flexural strength, flexural modulus, and elongation at break parameters reported by other researchers in their publications to compare while results were investigated at the same condition. 


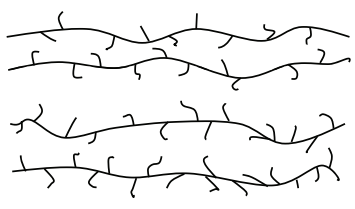

(a)

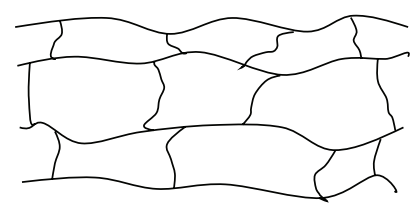

(b)

Figure 1: Construction of (a) thermoplastic polymer and (b) thermoset polymer.

\section{Material Properties}

According to the nature of oil palm which is not long enough to consider as long fiber, scientists used short length fibers or nanoparticle of OPFs in their researches so there is not any report about using long length of OPF as a continuous fiber concept. Several kinds of resins including thermoset or thermoplastic resins were used in studies by researchers; although, thermosets are much harder than thermoplastics and also using this kind of polymer is reasonable [14]. Some engineers made hybrid composites of OPF by the usage of other natural fibers or even synthetic fibers to enhance the properties of OPF. In this paper, the most important and significant results are considered and discussed.

2.1. OPF Fiber Properties. Oil palm empty fruit bunch fiber (OPF) was characterized in terms of tensile strength, Young's modulus, elongation at break, density, and so forth. Table 1 shows the results gathered from other researches. According to Table 1, it is clear that results reported by researchers are not identical because of variation in the kind of oil palm fiber used and also the irregular sectional area which fluctuates along the length of OPF [24]. Consequently, some of references reported wide range of value for mechanical properties. In addition, linear stress-strain diagram of OPF tensile behavior was reported by researchers, although, there is no unified diagram. However, comparison between OPF fibers is not the major purpose of this paper, and this paper focuses on the performances of OPF fiber in polymers (composites) for engineering aims.

2.2. Polymer Properties. Scientists use both thermoset and thermoplastic polymers for composites. These two polymers have their own properties and applications. Both of them are of long molecular chains but there is an important difference between these two types of resins during curing which is crosslinking. Thermoplastics polymer include individual chain of molecules without any chemical crosslink between them while thermosets polymer molecules have these crosslinks which is shown in Figure 1. So thermosets are usually used to construct structural elements because of the higher tensile strength and rigidity, and thermoplastics are considered for nonstructural products [25]. Due to researchers' publications, properties of polymers used in OPF composites are mentioned in Table 2. In this table, polypropylene is thermoplastic polymer and the rest are thermoset polymers.
TABLE 1: OPF fiber properties.

\begin{tabular}{|c|c|c|}
\hline Property & Value & Researcher \\
\hline \multirow{9}{*}{ Density $\left(\mathrm{gr} / \mathrm{cm}^{3}\right)$} & $0.7-1.55$ & {$[15]$} \\
\hline & 1.15 & {$[16]$} \\
\hline & 1.15 & {$[12]$} \\
\hline & 1.03 & {$[17]$} \\
\hline & 0.895 & {$[18]$} \\
\hline & $0.7-1.55$ & {$[6,19]$} \\
\hline & 1.07 & {$[20]$} \\
\hline & 1.4 & [21] \\
\hline & 1.51 & {$[22]$} \\
\hline \multirow{7}{*}{ Tensile strength $(\mathrm{MPa})$} & 71 & {$[12]$} \\
\hline & 377 & [17] \\
\hline & 24.9 & {$[18]$} \\
\hline & $100-400$ & {$[15]$} \\
\hline & 58.3 & [20] \\
\hline & $50-400$ & {$[6]$} \\
\hline & $240-550$ & [22] \\
\hline \multirow{5}{*}{ Young's modulus (GPa) } & 1.7 & {$[12]$} \\
\hline & $1-9$ & {$[6,15,19]$} \\
\hline & 2.75 & {$[17]$} \\
\hline & 0.48 & {$[20]$} \\
\hline & 3.2 & {$[21,22]$} \\
\hline \multirow{6}{*}{ Elongation at break (\%) } & 4 & {$[18]$} \\
\hline & 13.71 & [17] \\
\hline & 11 & {$[12]$} \\
\hline & $8-18$ & {$[6,15,19]$} \\
\hline & 12.21 & {$[20]$} \\
\hline & 14 & {$[21,22]$} \\
\hline
\end{tabular}

2.3. Chemical Fiber Treatment. The most important issue of biofiber polymer composite is the interfacial bonding of fiber and polymer caused by the hydrophilic nature of natural fiber against the hydrophobic nature of polymer which can be improved by chemical surface modification.

Generally, all researchers and manufacturers consider surface treatment for producing polymer composites by the usage of biofiber such as kenaf, jute, sisal, hemp, and OPF. Several chemical surface modifications of natural fiber have been reported to improve the interface bonding of fibermatrix by scientists including of alkaline treatment, silane treatment, acetylation, isocyanate. 
TABLE 2: Mechanical properties of polymers.

\begin{tabular}{|c|c|c|c|c|c|c|}
\hline Resin type & $\begin{array}{c}\text { Tensile strength } \\
(\mathrm{MPa})\end{array}$ & $\begin{array}{l}\text { Tensile modulus } \\
(\mathrm{MPa})\end{array}$ & $\begin{array}{c}\text { Elongation at break } \\
(\%)\end{array}$ & $\begin{array}{c}\text { Flexural strength } \\
(\mathrm{MPa})\end{array}$ & $\begin{array}{l}\text { Flexural modulus } \\
(\mathrm{MPa})\end{array}$ & Researchers \\
\hline Polyester $^{\mathrm{a}}$ & 38.44 & 999 & 3.84 & - & - & {$[20]$} \\
\hline Epoxy $^{\mathrm{a}}$ & 63 & 1371 & 5.8 & 105 & 3547 & {$[12]$} \\
\hline Polypropylene (PP) & 19.3 & 300 & - & 34.3 & 1300 & [23] \\
\hline Epoxy $^{b}$ & 62.49 & 1130 & 9 & - & - & {$[18]$} \\
\hline Epoxy $^{c}$ & - & - & - & 33.5 & 1040 & {$[6]$} \\
\hline Polyester ${ }^{\mathrm{b}}$ & - & - & - & 43.3 & - & [16] \\
\hline
\end{tabular}

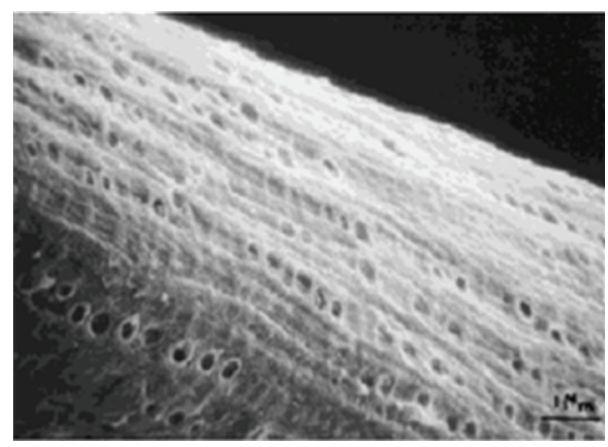

FIGURE 2: SEM image of alkali-treated OPF [11].

Alkaline treatment (mercerization) is a well-known chemical treatment of surface modification of natural fiber for making natural fiber reinforced polymer. This treatment removes lignin, hemicellulose, wax, and oils covering the surface of the fiber [26]

$$
\text { fiber }-\mathrm{OH}+\mathrm{NaOH}=\text { Fiber }-\mathrm{O}^{-} \mathrm{Na}^{+}+\mathrm{H}_{2} \mathrm{O}
$$

In alkaline treatment, fibers should be immersed in $\mathrm{NaOH}$ solution for a limited time. Alawar et al. [27] used different treatment process of alkaline treatment on the date palm fiber, and he reported that the best process was to utilize $1 \% \mathrm{NaOH}$ in $100^{\circ} \mathrm{C}$ water for 1 hour.

Mishra et al. [28] employed sisal fibers with 5\% and 10\% $\mathrm{NaOH}$, cyanoethylated and acetylated fiber surface treatment for fabricating of hybrid glass-sisal composite, and the result showed that the $5 \% \mathrm{NaOH}$ solution has the best effects on the interface bonding of composite. OPF was treated by $2 \%$ $\mathrm{NaOH}$ solution at $100^{\circ} \mathrm{C}$ for 30 minutes to improve surface conditions [16]. Joseph et al. [21, 22] used $5 \% \mathrm{NaOH}$ solution, silane treatment, and benzoyl chloride treatment, and they reported their observation of fiber surface by SEM method as follows: (1) fiber surface was changed to rough; (2) fiber porosity was increased because of removing the hemicellulose. These two factors caused a better shear connection between fiber and resin and resulted in better interfacial bonding. Besides, a significant attempt was done by Sreekala et al. [11] on the treatment of OPF by alkaline method and silan treatment. They stated that the silane treatment increased the tensile strength and modulus of individual OPF while the alkali treatment decrease slightly the tensile strength of OPF fiber and increase the tensile modulus.
Figures 2 and 3 show the surface of OPF after different chemical treatments

$$
\begin{aligned}
& \text { Fiber- } \mathrm{OH}+\mathrm{CH}_{3} \mathrm{COOH} \\
& \underset{\text { Conc. } \mathrm{H}_{2} \mathrm{SO}_{4}}{\stackrel{\left(\mathrm{CH}_{3} \mathrm{CO}\right)_{2} \mathrm{O}}{\longrightarrow}} \text { Fiber-O-O }-\stackrel{\mathrm{C}-\mathrm{CH}_{3}+\mathrm{H}_{2} \mathrm{O}}{\text { (Acetylation) }} \\
& \mathrm{CH}_{2} \mathrm{CHSi}(\mathrm{OH})_{3}+\mathrm{H}_{2} \mathrm{O}+\text { Fiber-OH }
\end{aligned}
$$

$$
\longrightarrow \mathrm{CH}_{2} \mathrm{CHSi}(\mathrm{OH})_{2} \mathrm{O}-\text { Fiber }+2 \mathrm{H}_{2} \mathrm{O}
$$

\section{Mechanical Properties of OPF Composites}

The major chemical components of OPF are 65\% cellulose, $19 \%$ lignin, and $2 \%$ ash. The most important properties of structural elements are tensile, flexural, and shear behavior of materials but authors could not find any report or document of shear properties of OPF composites. To improve the performance of OPF fiber in composites, scientists not only used several methods to enhance OPF properties such as surface treatment and sizing but also made composites by employing different resins and hybrid systems [15, 29-34]. Therefore, the results of experiments with the same fiber, polymer, and also the same conditions are compared to each other to gain a logical conclusion.

3.1. Tensile Properties of OPF Composites. Tensile strength and tensile modulus are considered as major properties of materials by engineers. So many researchers conducted to produce OPF composites by the usage of different polymers to test. Table 3 shows the result of their attempts. By considering the experimental results mentioned in Table 2 (polymer properties) and Table 3 (composite properties) and comparing them, it is clear that adding OPF fiber to polymer to make composite causes the reduction of tensile strength of pure resin; in other words, Rozman et al. [23] reported that by increasing the fiber content of OPF of $10 \%, 30 \%$, and $40 \%$ in polypropylene polymer, the tensile strength of neat resin 19.3 $\mathrm{MPa}$ was reduced to $19 \mathrm{MPa}, 12 \mathrm{MPa}$, and $7 \mathrm{MPa}$, 
TABLE 3: Tensile properties of OPF composites.

\begin{tabular}{|c|c|c|c|c|}
\hline Property & Fiber content & Polymer & Value & Researcher \\
\hline \multirow{11}{*}{$\begin{array}{l}\text { Tensile strength } \\
\text { (MPa) }\end{array}$} & $5 \%$ OPF & Epoxy $^{a}$ & 29.9 & {$[12]$} \\
\hline & $10 \%$ OPF & Polypropylene & 19 & [23] \\
\hline & $30 \%$ OPF & Polypropylene & 12 & [23] \\
\hline & $40 \%$ OPF & Polypropylene & 7 & [23] \\
\hline & $35 \%$ OPF & Epoxy $^{\mathrm{b}}$ & 47.8 & {$[18]$} \\
\hline & $55 \%$ OPF & Epoxy $^{\mathrm{b}}$ & 46.1 & {$[18]$} \\
\hline & $5 \%$ OPF & Polyester $^{\mathrm{a}}$ & 36.3 & [20] \\
\hline & $10 \% \mathrm{OPF}$ & Polyester ${ }^{\mathrm{a}}$ & 29.38 & {$[20]$} \\
\hline & $15 \% \mathrm{OPF}$ & Polyester $^{\mathrm{a}}$ & 31.5 & {$[20]$} \\
\hline & $20 \% \mathrm{OPF}$ & Polyester $^{\mathrm{a}}$ & 28.59 & {$[20]$} \\
\hline & $30 \%$ OPF & Polyester $^{\mathrm{a}}$ & 29.24 & {$[20]$} \\
\hline \multirow{12}{*}{$\begin{array}{l}\text { Tensile modulus } \\
(\mathrm{MPa})\end{array}$} & $5 \%$ OPF & Epoxy $^{a}$ & 1433 & {$[12]$} \\
\hline & $20 \% \mathrm{PF}$ & Epoxy $^{\mathrm{a}}$ & 1335 & {$[12]$} \\
\hline & $10 \% \mathrm{OPF}$ & Polypropylene & 560 & [23] \\
\hline & $30 \%$ OPF & Polypropylene & 615 & [23] \\
\hline & $40 \% \mathrm{OPF}$ & Polypropylene & 725 & [23] \\
\hline & $35 \%$ OPF & Epoxy $^{\mathrm{b}}$ & 1010 & {$[18]$} \\
\hline & $55 \%$ OPF & Epoxy ${ }^{b}$ & 1020 & {$[18]$} \\
\hline & $5 \% \mathrm{OPF}$ & Polyester $^{\mathrm{a}}$ & 1497 & {$[20]$} \\
\hline & $10 \% \mathrm{OPF}$ & Polyester $^{\mathrm{a}}$ & 2542 & {$[20]$} \\
\hline & $15 \%$ OPF & Polyester $^{\mathrm{a}}$ & 2358 & [20] \\
\hline & $20 \%$ OPF & Polyester $^{\mathrm{a}}$ & 2170 & [20] \\
\hline & $30 \%$ OPF & Polyester $^{\mathrm{a}}$ & 2308 & {$[20]$} \\
\hline
\end{tabular}

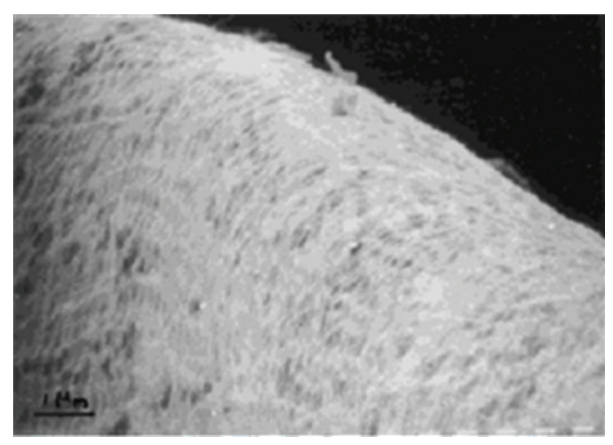

FIGURE 3: SEM image of silane-treated OPF [11].

respectively, but the tensile modulus of neat resin $300 \mathrm{MPa}$ was increased to $560 \mathrm{MPa}, 615 \mathrm{MPa}$, and $725 \mathrm{MPa}$, respectively. The reason is the incompatibility of PP and OPF and also irregularity of OPF size that these two factors cause the reduction of stress transfer through the matrix. The other efforts that have been done by Zuhri et al. [12] and Kalam et al. [18] revealed that using OPF fiber in Epoxy polymer has negative influence on tensile strength and tensile modulus on OPF composite in comparison to pure resin. As from the data shown in Tables 2 and 3, the tensile strength and tensile modulus of pure epoxy were $62.49 \mathrm{Mpa}$ and $1.13 \mathrm{Gpa}$ which have been reduced to $46 \mathrm{Mpa}$ and $1.02 \mathrm{GPa}$, respectively, because of replacing $55 \%$ of epoxy matrix volume by OPF.

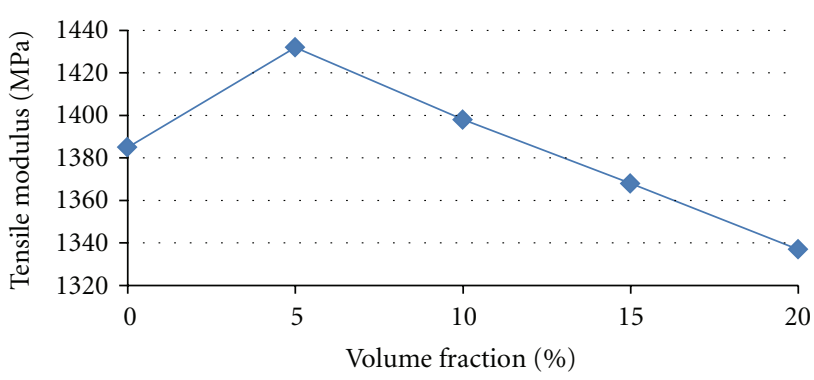

FIGURE 4: Tensile modulus versus fiber volume fraction in OPF/Epoxy composite (update from [12]).

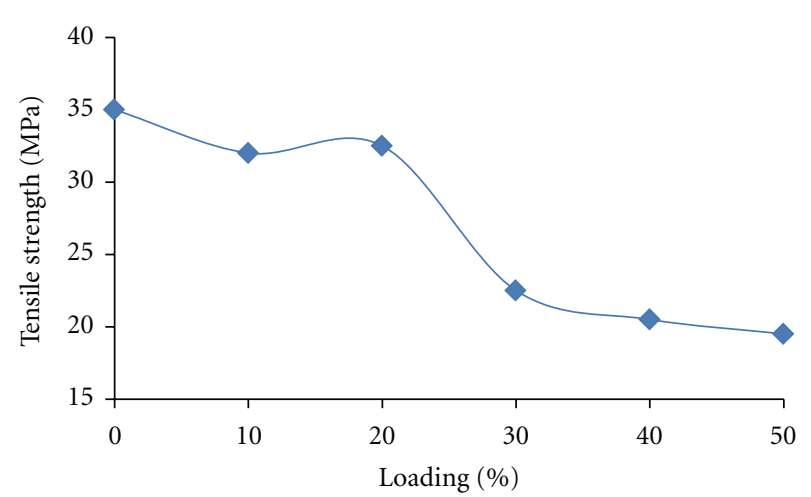

FIGURE 5: Tensile strength of OPF (EFB)/PP composite (update from [13]).

Chin [20] employed polyester polymer to evaluate the tensile properties of OPF composite. He exhibited that increasing the OPF fiber content in polyester resin up to $30 \%$ caused a decrease in tensile strength of composite in comparison to pure resin and tensile modulus of neat resin an increase in OPF composite about $56.7 \%$. Also, the tensile modulus of $\mathrm{OPF} /$ Epoxy composite test results reported by Zuhri et al. [12] are shown in Figure 4 . This figure presents that by adding OPF to epoxy resin up to $5 \%$ volume fraction can increase the tensile modulus but increasing the OPF volume fraction more than $5 \%$ has a result of reduction in tensile modulus. Figure 5 shows the finding out of Khalid et al. [13] in order to tensile strength of $\mathrm{OPF} / \mathrm{PP}$ composite that exhibits a negative trend of OPF increasing on the tensile strength. In fact, the experiments results mentioned demonstrate that adding OPF fiber to polymer to enhance tensile strength of resin by making OPF composite are not recommended because the tensile strength would be decreased by increasing of OPF fiber content in composite. On the other hand, OPF fiber can improve the tensile modulus of PP and Polyester resin but it does not have any positive effect on the tensile modulus of Epoxy resin by making OPF composite.

In addition, by considering the internal strain energy (100), the internal strain energy of composites can be estimated. According to (100), when the ultimate tensile strength of composite is reduced while the tensile modulus is increased, the internal strain energy of composite would be decreased. In other words, adding OPF to polymer for making composite or to existing composite for making hybrid 
TABLE 4: Flexural properties of OPF composites.

\begin{tabular}{|c|c|c|c|c|}
\hline Property & Fiber content & Polymer & Value & Researcher \\
\hline \multirow{9}{*}{ Flexural strength (MPa) } & $\begin{array}{c}\text { 6\% OPF, 9\% GF } \\
\text { OPF/GF/GF } 3 \text { Layers }\end{array}$ & Polyester ${ }^{\mathrm{b}}$ & 163.3 & {$[16]$} \\
\hline & $\begin{array}{c}\text { 14\% OPF, 6\% GF } \\
\text { OPF/OPF/GF } 3 \\
\text { Layers }\end{array}$ & Polyester $^{\mathrm{b}}$ & 146.7 & {$[16]$} \\
\hline & $18 \%$ OPF & Polyester ${ }^{\mathrm{b}}$ & 33.9 & {$[16]$} \\
\hline & $5 \%$ OPF & Epoxy $^{\mathrm{a}}$ & 40.9 & {$[12]$} \\
\hline & $10 \% \mathrm{OPF}$ & Epoxy $^{a}$ & 51 & {$[12]$} \\
\hline & $40 \%$ OPF & Epoxy $^{\mathrm{a}}$ & 41.7 & {$[6]$} \\
\hline & $40 \%$ OPF/Jute/OPF & Epoxy $^{c}$ & 44.3 & {$[6]$} \\
\hline & $40 \%$ Jute/OPF/Jute & Epoxy $^{c}$ & 49 & {$[6]$} \\
\hline & $40 \%$ Jute & Epoxy $^{\mathrm{c}}$ & 75.5 & {$[6]$} \\
\hline \multirow{4}{*}{ Flexural modulus (MPa) } & $40 \%$ OPF & Epoxy $^{c}$ & 2300 & {$[6]$} \\
\hline & $40 \%$ OPF/Jute/OPF & Epoxy $^{c}$ & 2680 & {$[6]$} \\
\hline & $40 \%$ Jute/OPF/Jute & Epoxy $^{c}$ & 3070 & {$[6]$} \\
\hline & Jute & Epoxy $^{\mathrm{c}}$ & 4320 & {$[6]$} \\
\hline
\end{tabular}

composite causes the reduction in tensile strength and increasing in tensile modulus that this new product has lower potential of internal strain energy than the pure resin or initial composite, respectively:

$$
\Delta U=\frac{\sigma^{2}}{2 E}=\frac{1}{2} \sigma \varepsilon
$$

where, $\Delta U, \sigma, \varepsilon$, and $E$ are the potential of internal strain energy, tensile stress, tensile strain, and tensile modulus, respectively.

3.2. Flexural Properties of OPF Composites. Table 4 shows experimental results from different researches in terms of flexural properties of OPF composites by employing of different resins. Karina et al. [16] attempted to investigate OPF composite by polyester resin that their study showed adding OPF fiber to polymer to make OPF composite causes lower flexural strength than neat resin which was used in composite. On the other hand, Jawaid et al. [19] claim that OPF fiber can improve the flexural modulus of Epoxy polymer while Zuhri et al. [12] declare that OPF fiber decreases the flexural modulus of Epoxy polymer. Figure 6 shows the flexural modulus of OPF polypropylene composite reported by Khalid et al. [13] who revealed that the increasing of OPF fiber in OPF composite causes the increasing in the flexural modulus. In other words, OPF fiber can increase the flexural modulus of pure polypropylene resin and also decrease the flexural strength of pure polypropylene resin when OPF is added to pure polypropylene. This is a common phenomenon that the addition of filler to polymer results the greater modulus while the filler incorporation in the PP matrix causes an interruption in the stress transferring because of the lack of interfacial interaction between OPF and PP matrix due to the polar nature of OPF against the nonpolar groups of PP resin.

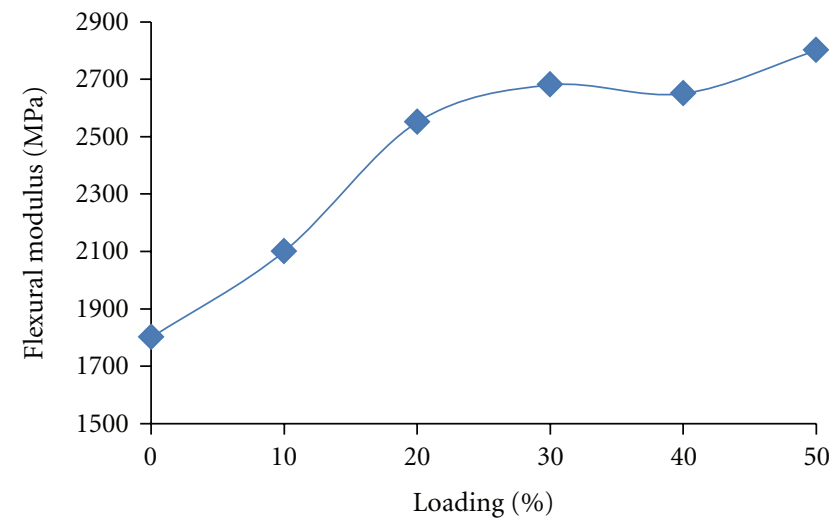

FIGURE 6: Flexural modulus of OPF (EFB)/PP composite (update from [13]).

3.3. Hybrid Composites by OPF. Rozman et al. [23] reported their experiences of changing the fiber content of Glass fiber and OPF fiber in hybrid polypropylene composites which are shown in Figures 7, 8, 9, and 10 that these figures mean when OPF fiber content in hybrid composites increase, the tensile and flexural properties of hybrid composites decrease. Furthermore, Sreekala et al. [15] conducted valuable tests by using of glass fiber, OPF fiber (hybrid composite), and phenol formaldehyde resin that the results are shown in Figures 11, 12 , and 13 which present that OPF has a negative effect on hybrid composite properties. It is reported that at high OPF loading, the fabricating is very difficult and the dispersion becomes very poor. Meanwhile, compression molding causes some transverse fiber orientation in the surface area which is a decisive factor in the mechanical performance of the composite. The possibility for this type of fiber orientation is decreased at higher fiber loading. Composite tensile strength 


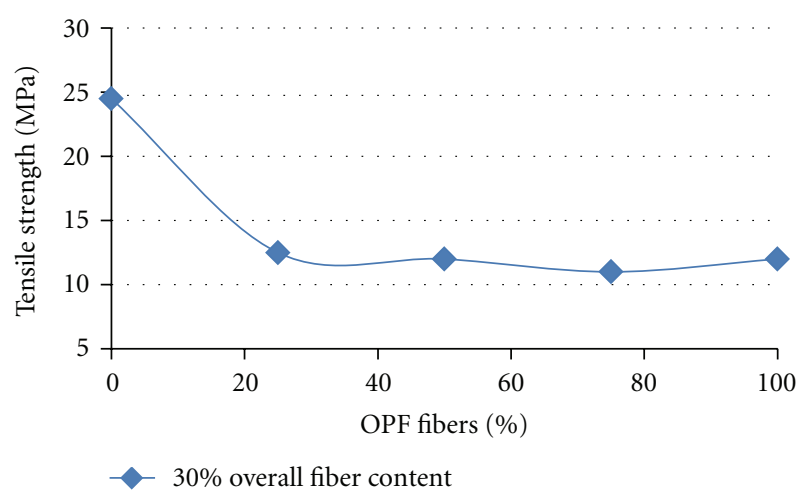

Figure 7: Tensile strength as a function of OPF content in hybrid glass fiber/OPF (EFB) by PP (update from [23]).

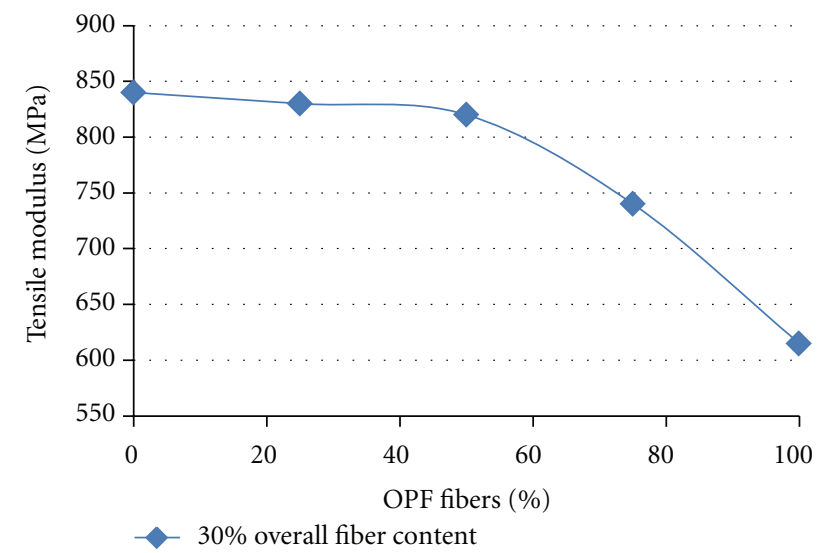

Figure 8: Tensile strength as a function of OPF content in hybrid glass fiber/OPF (EFB) by PP (update from [23]).

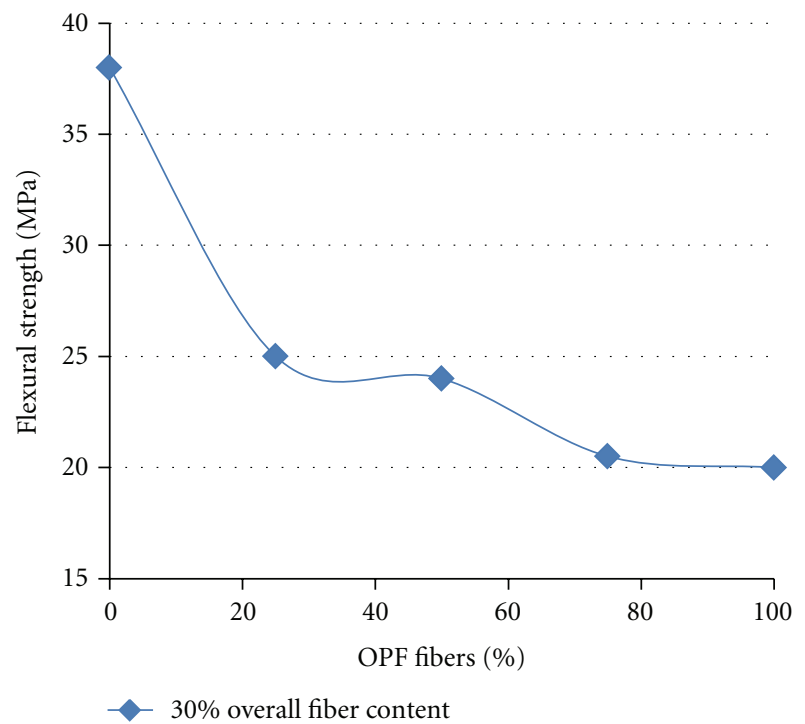

FIgURE 9: The effect of OPF content on the flexural strength of hybrid GF/OPF (EFB) by PP (update from [23]).

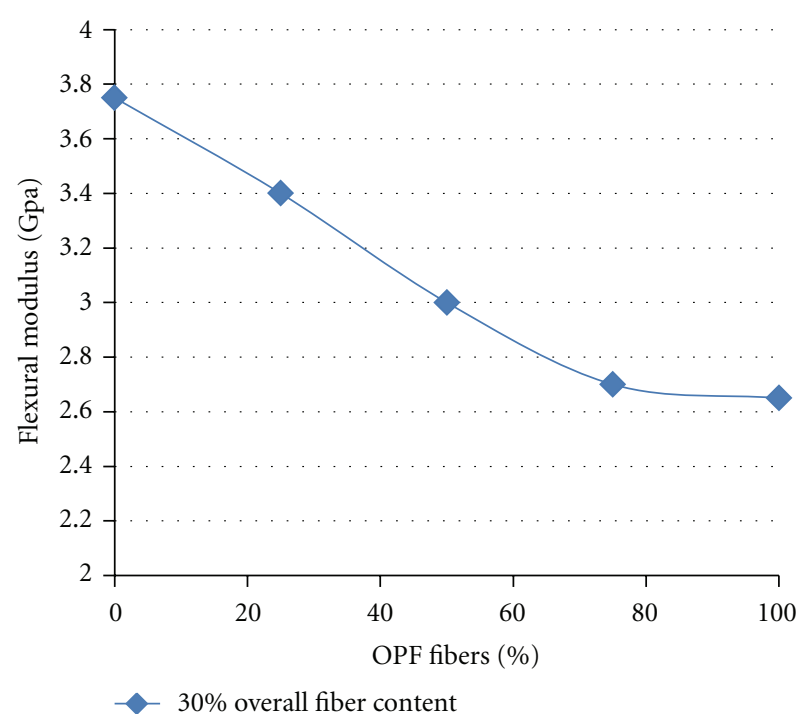

FIGURE 10: The effect of OPF content on the flexural modulus of hybrid GF/OPF (EFB) by PP (update from [23]).

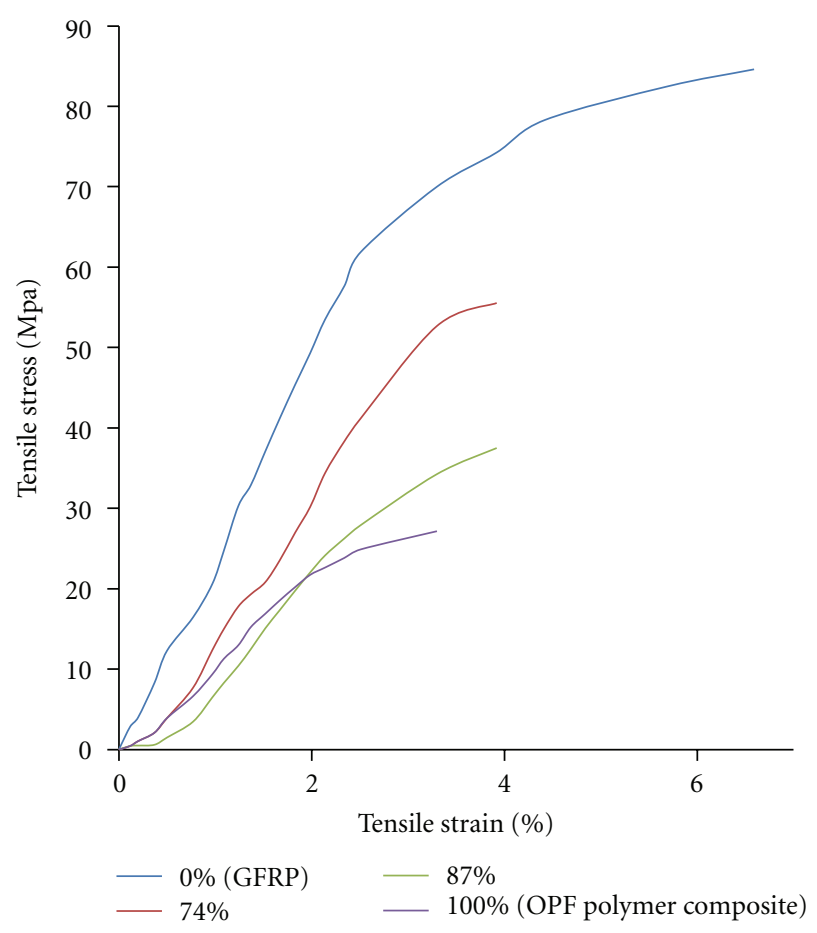

FIGURE 11: Tensile stress-strain diagram of hybrid GF/OPF composites by PF polymer due to different OPF volume content (update from [15]).

slightly increases with increasing interlaminar shear strength. Furthermore, incorporation of $74 \%$ volume fraction of the OPF fiber in the hybrid leads to composites having a higher tensile strength. So, maximum intermingling of the fibers and higher compatibility are achieved at this volume fraction of fibers. According to Figure 13, the incorporation of a 55\% volume fraction of OPF to hybrid composites has a good 


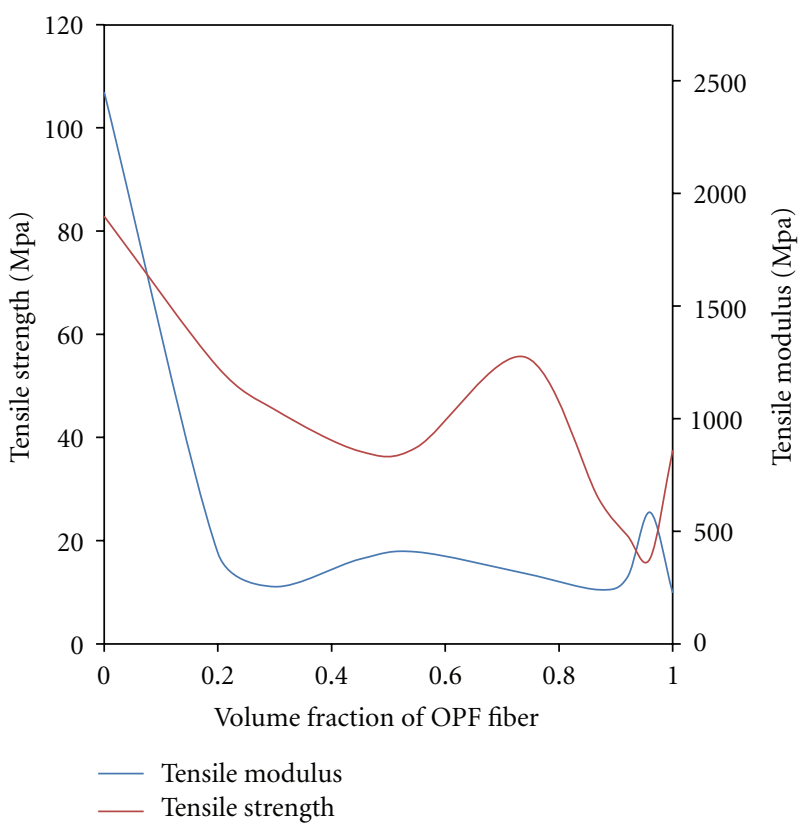

FIGURE 12: Variation in tensile properties of hybrid GF/OPF composite by PF polymer (update from [15]).

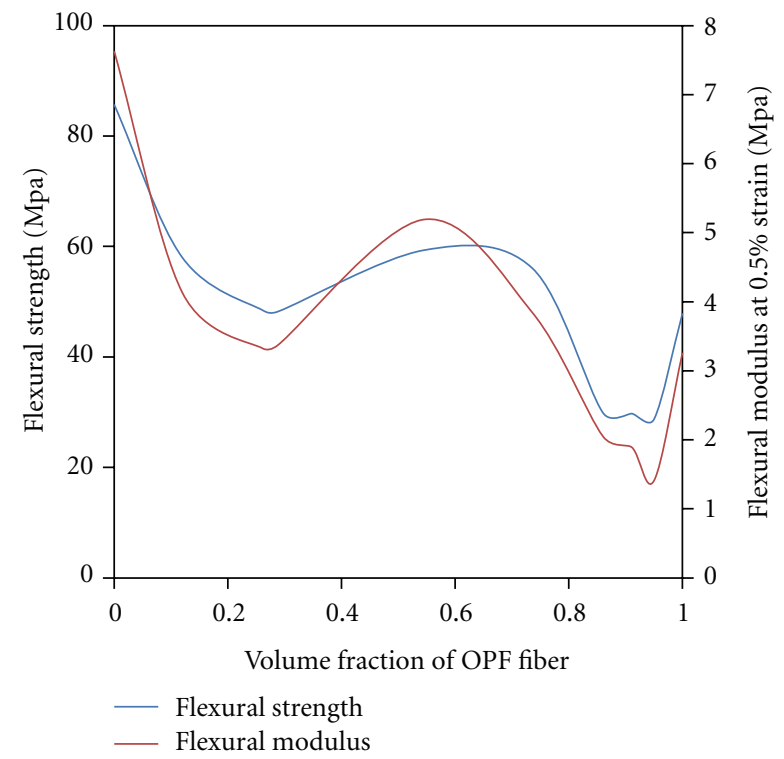

FIGURE 13: Variation in flexural properties of hybrid GF/OPF composite by PF polymer (update from [15]).

flexural performance. This is evident from the unique stressstain behavior of the composite at this fiber loading [15]. Moreover, Karina et al. [16] reported that increasing of OPF fiber to make a hybrid composite by using of glass fiber is strictly unreasonable (Table 4). In addition, Jawaid et al. $[6,19]$ reported their experiences about the hybrid composite by using of two natural fibers, namely, OPF and Jute fiber that the results support precisely the previous results about hybrid composite by using of OPF in terms of the reduction hybrid mechanical properties by increasing the OPF content.

\section{Conclusion}

Based on the literature, oil palm fiber generally has low mechanical properties and also can be used as reinforcement in polymer composite with lowaspect ratio that these two main reasons cause lower mechanical properties of OPF composite in comparison with the initial polymer. By comparing the result of previous studies mentioned in this paper, it can be concluded that OPF fiber has different influence on polymer and composite properties as well. The outcomes of this study consist of the following.

(1) The tensile strength of OPF polymer composites is less than the tensile strength of pure resin which was used in the composite generally.

(2) The tensile modulus of OPF polymer composites is higher than the tensile modulus of some pure resins such as polypropylene or polyester which was used in the composite but there is no significant result about increasing the tensile modulus of OPF Epoxy composite as compared to pure epoxy.

(3) Due to increasing of tensile modulus and decreasing of tensile strength of OPF polymer composites, the elongation at break of OPF composite is reduced as compared to pure resin which was used in the composite.

(4) OPF polymer composite has lower flexural strength and higher flexural modulus than pure resin which was used in making composite.

(5) Increasing the tensile modulus while the ultimate tensile strength is decreased causes the reduction of strain energy of composite. In other words, the OPF polymer composite can absorb load less than pure resin.

(6) OPF fiber reduces the mechanical properties of composites when it is added to any composite to make a new hybrid.

(7) In general concept, because of the lower mechanical properties of OPF fiber in comparison to other fibers used usually, using of OPF fiber can only reduce the new hybrid composite mechanical properties.

\section{Recommendation}

Information on the effect of OPF fiber on other polymers like vinyl ester and hybridization to other fibers such as carbon fiber, steel wire, and other natural fibers is limited although it is possible to have an estimation of the mechanical properties due to previous study. Also, to make new composites by employing new thermoset polymers does not seem reasonable for structural aims. Moreover, previous studies show the impact properties of OPF composites are better than pure resin that it can be an interesting factor for special industries for using new material to make products such as car bumper and dashboard. However, more studies are needed to find out and verify the predictions. In addition, the use of OPF composite in secondary structural element 
need to be investigated and also scientific data about fiber production method, aging, environmental effects of this type of fiber (OPF) composite should be completed in future.

\section{Acknowledgments}

The work is financed by Zamalah/Institutional scholarship provided from the Universiti Teknologi Malaysia and the Ministry of Higher Education of Malaysia.

\section{References}

[1] X. Huang, V. Birman, A. Nanni, and G. Tunis, "Properties and potential for application of steel reinforced polymer and steel reinforced grout composites," Composites B, vol. 36, no. 1, pp. 73-82, 2005.

[2] M. Pecce, F. Ceroni, A. Prota, and G. Manfredi, "Response prediction of RC beams externally bonded with steel-reinforced polymers," Journal of Composites for Construction, vol. 10, no. 3, pp. 195-203, 2006.

[3] Y. F. Wu, J. H. Yan, Y. W. Zhou, and Y. Xiao, "Ultimate strength of reinforced concrete beams retrofitted with hybrid bonded fiberreinforced polymer," ACI Structural Journal, vol. 107, no. 4, pp. 451-460, 2010.

[4] J. Li, S. L. Bakoss, B. Samali, and L. Ye, "Reinforcement of concrete beam-column connections with hybrid FRP sheet," Composite Structures, vol. 47, no. 1-4, pp. 805-812, 1999.

[5] L. C. Hollaway, "A review of the present and future utilisation of FRP composites in the civil infrastructure with reference to their important in-service properties," Construction and Building Materials, vol. 24, no. 12, pp. 2419-2445, 2010.

[6] M. Jawaid, H. P. S. A. Khalil, and A. A. Bakar, "Mechanical performance of oil palm empty fruit bunches/jute fibres reinforced epoxy hybrid composites," Materials Science and Engineering A, vol. 527, no. 29-30, pp. 7944-7949, 2010.

[7] M. Pervaiz and M. M. Sain, "Carbon storage potential in natural fiber composites," Resources, Conservation and Recycling, vol. 39, no. 4, pp. 325-340, 2003.

[8] M. A. de Farias, M. Z. Farina, A. P. T. Pezzin, and D. A. K. Silva, "Unsaturated polyester composites reinforced with fiber and powder of peach palm: mechanical characterization and water absorption profile," Materials Science and Engineering C, vol. 29, no. 2, pp. 510-513, 2003.

[9] G. Cicala, G. Cristaldi, G. Recca, G. Ziegmann, A. El-Sabbagh, and M. Dickert, "Properties and performances of various hybrid glass/natural fibre composites for curved pipes," Materials and Design, vol. 30, no. 7, pp. 2538-2542, 2009.

[10] S. Shinoj, R. Visvanathan, S. Panigrahi, and N. Varadharaju, "Dynamic mechanical properties of oil palm fibre (OPF)-linear low density polyethylene (LLDPE) biocomposites and study of fibre-matrix interactions," Biosystems Engineering, vol. 109, no. 2, pp. 99-107, 2011.

[11] M. S. Sreekala, M. G. Kumaran, and S. Thomas, "Oil palm fibers: morphology, chemical composition, surface modification, and mechanical properties," Journal of Applied Polymer Science, vol. 66, no. 5, pp. 821-835, 1997.

[12] M. Zuhri, M. Yusoff, S. M. Sapuan, N. Ismail, and R. Wirawan, "Mechanical properties of short random oil palm fibre reinforced epoxy composites," Sains Malaysiana, vol. 39, no. 1, pp. 87-92, 2010.

[13] M. Khalid, C. T. Ratnam, T. G. Chuah, S. Ali, and S. Y. C. Thomas, "Comparative study of polypropylene composites reinforced with oil palm empty fruit bunch fiber and oil palm derived cellulose," Materials and Design, vol. 29, no. 1, pp. 173178, 2008.

[14] C. Varga, N. Miskolczi, L. Bartha, and G. Lipóczi, "Improving the mechanical properties of glass-fibre-reinforced polyester composites by modification of fibre surface," Materials and Design, vol. 31, no. 1, pp. 185-193, 2010.

[15] M. S. Sreekala, J. George, M. G. Kumaran, and S. Thomas, "The mechanical performance of hybrid phenol-formaldehydebased composites reinforced with glass and oil palm fibres," Composites Science and Technology, vol. 62, no. 3, pp. 339-353, 2002.

[16] M. Karina, H. Onggo, A. H. D. Abdullah, and A. Syampurwadi, "Effect of oil palm empty fruit bunch fiber on the physical and mechanical properties of fiber glass reinforced polyester resin," Journal of Biological Sciences, vol. 8, no. 1, pp. 101-106, 2008.

[17] K. M. M. Rao and K. M. Rao, "Extraction and tensile properties of natural fibers: vakka, date and bamboo," Composite Structures, vol. 77, no. 3, pp. 288-295, 2007.

[18] A. Kalam, B. B. Sahari, Y. A. Khalid, and S. V. Wong, "Fatigue behaviour of oil palm fruit bunch fibre/epoxy and carbon fibre/ epoxy composites," Composite Structures, vol. 71, no. 1, pp. 3444, 2005.

[19] M. Jawaid, H. P. S. A. Khalil, and A. A. Bakar, "Woven hybrid composites: tensile and flexural properties of oil palm-woven jute fibres based epoxy composites," Materials Science and Engineering A, vol. 528, no. 15, pp. 5190-5195, 2011.

[20] L. S. Chin, Characterization of natural fiber polymer composites for structural application [dissertation], Universiti Teknologi Malaysia, Johor Bahru, Malaysia, 2008.

[21] S. Joseph, P. A. Sreekumar, J. M. Kenny, D. Puglia, S. Thomas, and K. Joseph, "Oil palm microcomposites: processing and mechanical behavior," Polymer Engineering and Science, vol. 50, no. 9, pp. 1853-1863, 2010.

[22] S. Joseph, S. P. Appukuttan, J. M. Kenny, and D. Puglia, "Dynamic mechanical properties of oil palm microfibril-reinforced natural rubber composites," Journal of Applied Polymer Science, vol. 117, no. 3, pp. 1298-1308, 2010.

[23] H. D. Rozman, G. S. Tay, R. N. Kumar, A. Abusamah, H. Ismail, and I. Z. A. Mohd, "Polypropylene-oil palm empty fruit bunch-glass fibre hybrid composites: a preliminary study on the flexural and tensile properties," European Polymer Journal, vol. 37, no. 6, pp. 1283-1291, 2001.

[24] A. S. Virk, W. Hall, and J. Summerscales, "Failure strain as the key design criterion for fracture of natural fibre composites," Composites Science and Technology, vol. 70, no. 6, pp. 995-999, 2010.

[25] H. V. S. GangaRao, N. Taly, and P. V. Vijay, Reinforced Concrete Design with FRP Composites, Taylor \& Francis Group, Boca Raton, Fla, USA.

[26] X. Li, L. G. Tabil, and S. Panigrahi, "Chemical treatments of natural fiber for use in natural fiber-reinforced composites: a review," Journal of Polymers and the Environment, vol. 15, no. 1, pp. 25-33, 2007.

[27] A. Alawar, A. M. Hamed, and K. Al-Kaabi, "Characterization of treated date palm tree fiber as composite reinforcement," Composites B, vol. 40, no. 7, pp. 601-606, 2009.

[28] S. Mishra, A. K. Mohanty, L. T. Drzal et al., "Studies on mechanical performance of biofibre/glass reinforced polyester hybrid composites," Composites Science and Technology, vol. 63, no. 10, pp. 1377-1385, 2003. 
[29] C. A. S. Hill and H. P. S. A. Khalil, "Effect of fiber treatments on mechanical properties of coir or oil palm fiber reinforced polyester composites," Journal of Applied Polymer Science, vol. 78, pp. 1685-1697, 2000.

[30] S. Zakaria and L. K. Poh, "Polystyrene-benzoylated EFB reinforced composites," Polymer, vol. 41, no. 5, pp. 951-962, 2002.

[31] R. Agarwal, N. S. Saxena, K. B. Sharma, S. Thomas, and M. S. Sreekala, "Temperature dependence of effective thermal conductivity and thermal diffusivity of treated and untreated polymer composites," Journal of Applied Polymer Science, vol. 89, no. 6, pp. 1708-1714, 2003.

[32] A. A. Bakar and N. Baharulrazi, "Mechanical properties of benzoylated oil palm empty fruit bunch short fiber reinforced poly(vinyl chloride) composites," Polymer, vol. 47, no. 10, pp. 1072-1079, 2008.

[33] A. A. Bakar, A. Hassan, and A. F. M. Yusof, "The effect of oil extraction of the oil palm empty fruit bunch on the processability, impact, and flexural properties of PVC-U composites," International Journal of Polymeric Materials, vol. 55, no. 9, pp. 627-641, 2006.

[34] S. Shinoj, R. Visvanathan, S. Panigrahi, and M. Kochubabu, "Oil palm fiber (OPF) and its composites: a review," Industrial Crops and Products, vol. 33, no. 1, pp. 7-22, 2011. 

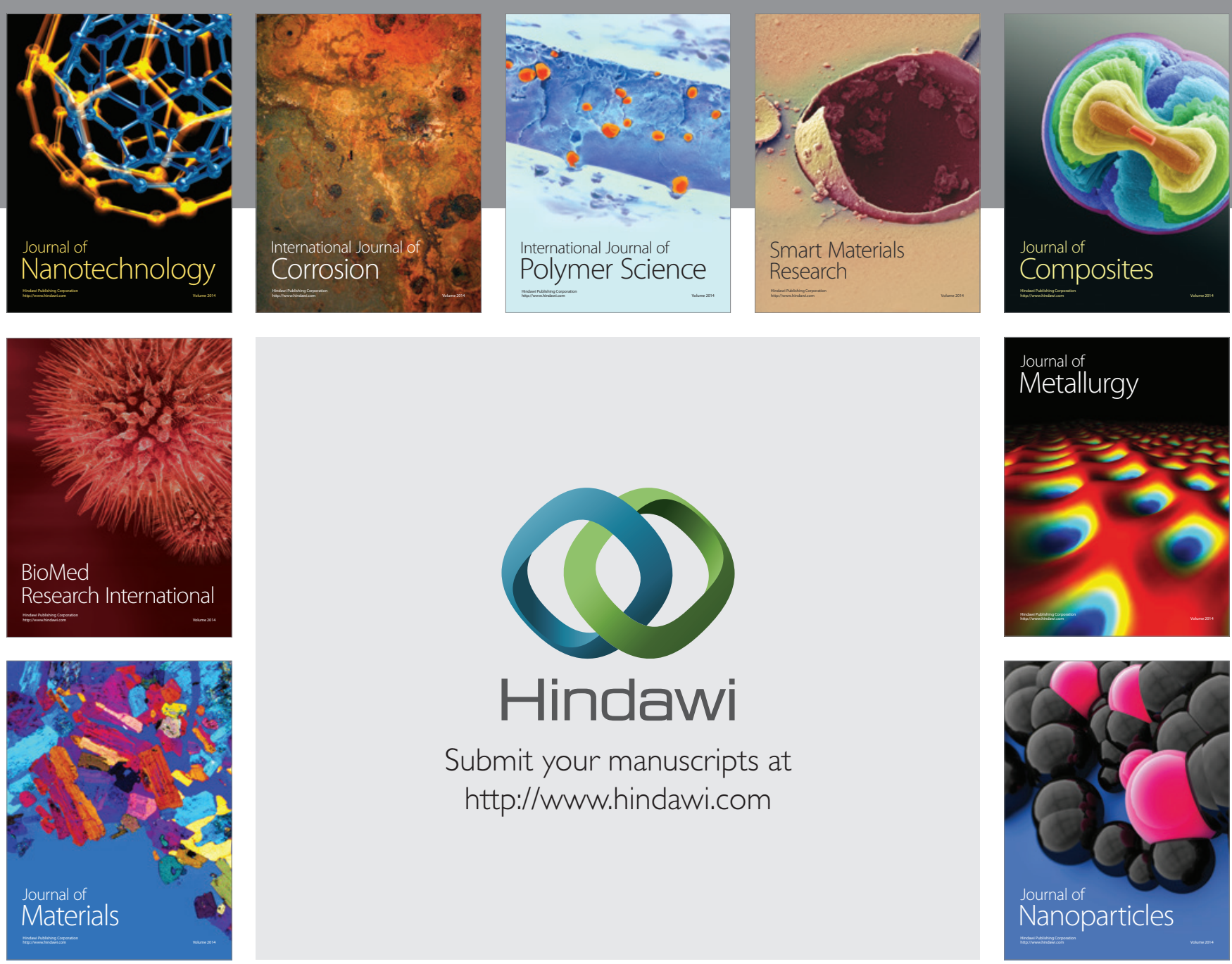

Submit your manuscripts at http://www.hindawi.com
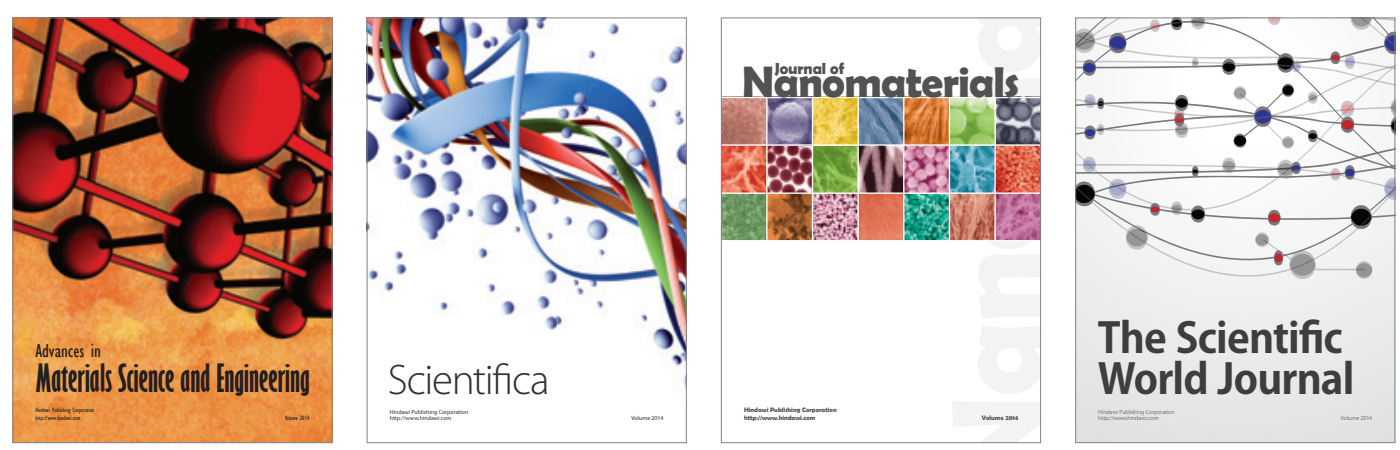

\section{The Scientific World Journal}
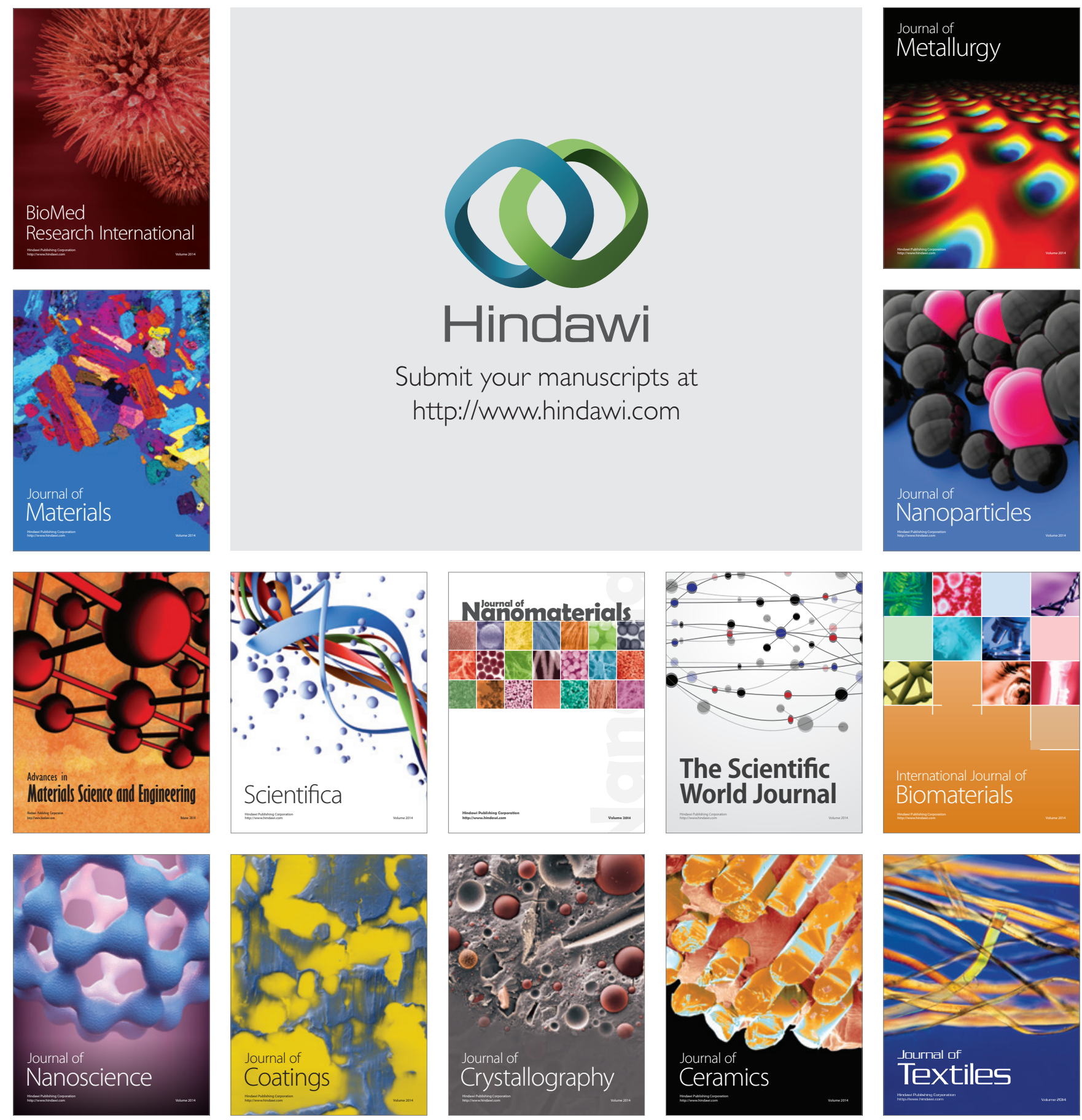